\title{
A abordagem sistêmica do processo generativo da forma aplicada ao projeto em Design
}

The systemic approach of the generative process of the form applied to the project in Design

\author{
> André Ximenes Moreira Nobre \\ Universidade Federal do Ceará, Brasil \\ andreximenesm@gmail.com
}

> Matheus Henrique do Vale Alencar

Universidade Federal do Ceará, Brasil

matheusawe@gmail.com

\author{
Dara Maria de Araújo Machado \\ Universidade Federal do Ceará, Brasil \\ lara_hp@hotmail.com
}

\begin{abstract}
The study addresses Shape Grammar as analytic and generative project methodology in Design. In order to authenticate the influence of these generation laws in design practice, the works of some artists of the Bauhaus school were analyzed. Furthermore, the study shows the importance of the designer in the conception process of his project, from the use of the identified grammar as generative tool for new products.
\end{abstract}

Keywords: Gramática da forma | Bauhaus | Autopoiese | Ato projetual .

\section{Introdução}

No presente artigo, pretende-se abordar a Gramática da Forma e sua relaçâa com a prática de projeto em Design. Essa relaçáo será apresentada com foco nas obras de alguns artistas da escola Bauhaus, a partir de análises das mesmas na busca por uma unidade de linguagem e possíveis regras que nortearam a prática projetual. Posteriormente, serão apresentadas algumas aplicaçóes de abordagem generativa, utilizando as regras identificadas para a produção de novos produtos, ressaltando a importância da subjetividade do designer no processo de concepçáo projetual por meio de um experimento estético. A partir dessa análise, a gramática construída serviu tanto para codificar o processo existente na produção de alguns artistas como também para construir uma ferramenta generativa de auxílio ao projeto que incorporou algumas regras advindas das obras analisadas.

Desenvolvida em 1972 por George Stiny e James Gips, a Gramática da Forma consiste em um sistema de geraçáo de formas baseado em regras. É um conjunto de formas que são aplicadas passo a passo para gerar um agrupamento ou uma linguagem de formas. Segundo CELANI (2006), ela pode ser constituída por: vocabulário de formas, regras de composição e uma forma inicial para dar início à aplicação da gramática. Ela lida com transformaçóes euclidianas e suas principais operaçôes são a translação, rotação, espelhamento e roto-translação. Além disso, ela pode ser ao mesmo tempo generativa e descritiva, pois as regras da gramática podem tanto gerar formas, como as próprias regras podem ser descriçóes de formas já existentes.
O termo "projeto" é uma palavra oriunda do termo em latim projectum que significa "algo lançado à frente". O projeto em design é uma ação que se baseia em uma análise do presente e, a partir disso, propor soluçóes voltadas para o futuro com base nos problemas encontrados. Portanto, ele é intrinsecamente associado à inovação. Além disso, o ato projetual deve ser sistêmico, com uma abordagem mais holística para sua maior efetividade. Segundo BONSIEPE (1997), o design pode se manifestar em qualquer área do conhecimento, sendo o ato projetual orientado ao futuro e à inovação. Além disso, ele afirma que o domínio central do design se encontra na interface, que é o espaço em que se dá a interaçấo entre corpo, objeto e objetivo da ação.

Criada em 1929, a Bauhaus foi uma escola situada na Alemanha que combinava arquitetura, design, pintura, escultura, dentre outras manifestaçóes artísticas, no propósito de criar uma arte unificada. Essa unificação se daria por um retorno às origens, a busca pela simplicidade, a valorização da funcionalidade em detrimento ao excesso ornamentativo, etc. Segundo LUPTON e ABBOTT MILLER (2008), a Bauhaus se baseava nas formas puras do triângulo, quadrado e círculo e nas cores primárias (vermelho, amarelo e azul) para criar uma gramática fundamental da visualidade. O interesse nessas formas primárias evidenciava a busca por aspectos elementares, essenciais e irredutíveis na prática projetual.

Optou-se aqui por abordar a relação entre Gramática da Forma e projeto em design no contexto da Bauhaus, pois, nessa época, o conceito de uma produção a partir de um vocabulário de formas e de um conjunto de regras de aplicação ainda não havia 
sido formalizado. Entretanto, é possível notar que essa prática já se fazia presente na linguagem da obra de alguns artistas, que criaram peças icônicas, onde se pode identificar uma unidade formal que permeia a maior parte de seus trabalhos. Com base nisso, foi possível analisar e descrever essas formas, sugerindo regras de formação e criando uma possível gramática da forma norteadora da produção e, partir disso, propor uma ferramenta generativa de novos produtos.

\section{Desenvolvimento}

A partir de pesquisas bibliográficas e experimentais, buscou-se atestar a potência e a importância da gramática da forma como metodologia de projeto, e a influência e interferência do designer no processo de concepção do produto. Embora não seja generalista, a gramática da forma pode vir a suprir demandas diretas dentro de um projeto. O projeto vai se auto-gerar, mas ao mesmo tempo é passível de interferência. É dever do projetista selecionar aquilo que lhe convém.

No caso da Bauhaus, por exemplo, mesmo que de modo intuitivo, a utilizaçáo de formas simples e algumas regras específicas de aplicação das mesmas auxiliou no intuito de seguir os princípios da escola, prezando pela funcionalidade e o caráter universal. As obras de alguns artistas apresentavam uma linguagem própria, pois normalmente se voltavam para a produção em série, a racionalização, o funcionalismo, a retirada de ornamentos em excesso, dentre outros. Além disso, a forma também era influenciada pelas novas descobertas no setor de materiais e processos de fabricação. Como exemplo disso, tem-se o aço tubular, que propiciava um aspecto de continuidade, elegância e clareza nos objetos.

A partir disso, identificou-se uma lógica de geração nos sistemas projetuais desses artistas, um possível conjunto de regras por meio das quais se poderiam gerar diversas combinaçôes formais aplicadas a produtos. Nesse exemplo, a gramática apresenta-se como uma ferramenta de geração espontânea de formas, regida pelo designer, na qual é escolhida a forma inicial, as regras a serem utilizadas e até que ponto serão aplicadas. Este sistema projetual se retrogera tornando mais rápida a criação de novos objetos e era utilizado de modo quase intuitivo pelos designers e arquitetos da Bauhaus, criando uma linguagem própria para a obra da época. Essa noção de um sistema de geração espontânea de formas que se retrogera pode ser facilmente compreendida ao traçar um paralelo com o conceito da autopoiese.

Esse termo cunhado por Maturana e Varela em 1974 significa autoprodução e foi inicialmente utilizado para explicar fenômenos e relaçóes biológicas. A autopoiese permite a compreensão de que um sistema pode se autorregular e se autogerir espontaneamente na natureza. Um sistema autopoiético é, simultaneamente, produtor e produto, sendo assim autônomo. Entretanto, esse sistema está sujeito a influências do meio e recorre a ele, sendo autônomo e também dependente, marcando assim uma condição paradoxal. $\mathrm{O}$ pensamento linear, que analisa as partes separadamente, sem levar em conta as relaçóes estabelecidas, é insuficiente na compreensão plena desses sistemas. Logo, para o pleno entendimento da autopoiese, é necessário um raciocínio sistêmico. Esse pensamento holístico também se faz presente no ato projetual em design. Contando com a influência do designer no processo criativo, alguns projetos podem ser alimentados pela gramática da forma, que atua de modo autopoiético, como produtora e produto ao mesmo tempo.

Sob a ótica da gramática da forma analítica, dentre os mais diversos artistas da Bauhaus, optou-se por focar a análise na produção de Marianne Brandt e Marcel Breuer. Marianne Brandt, nascida na Alemanha em 1893, foi pintora, fotógrafa, escultora e designer que estudou na Bauhaus. Ela buscou em seus projetos a racionalização e padronizaçáo da forma, visando maior produtividade industrial. Em relação ao aspecto formal de sua obra, criava objetos resultantes de sólidos de revoluçâo, ou seja, sólidos conseguintes da rotação de formas geométricas em torno do próprio eixo (Figura 1.1). O Cinzeiro (1926), por exemplo, é resultado da revolução de um triângulo subtraído de um retângulo e uma semicircunferência (Figura 1.2).

Quanto a Marcel Breuer, sua obra consiste basicamente em garantir a plena funcionalidade de seus objetos, sem muitos ornamentos, privilegiando a universalidade e a produção industrial, seguindo à risca os preceitos da Bauhaus. Nascido na Hungria em 1902, foi arquiteto e designer, fazendo parte da primeira geração de alunos da escola. Elementos formais como a "linha" (tubo) e o "retângulo" (prisma) estão constantemente presentes em seus artefatos (Figura 2.1). Muitos objetos feitos por Breuer, por exemplo as cadeiras, têm muito de sua forma determinada também pela

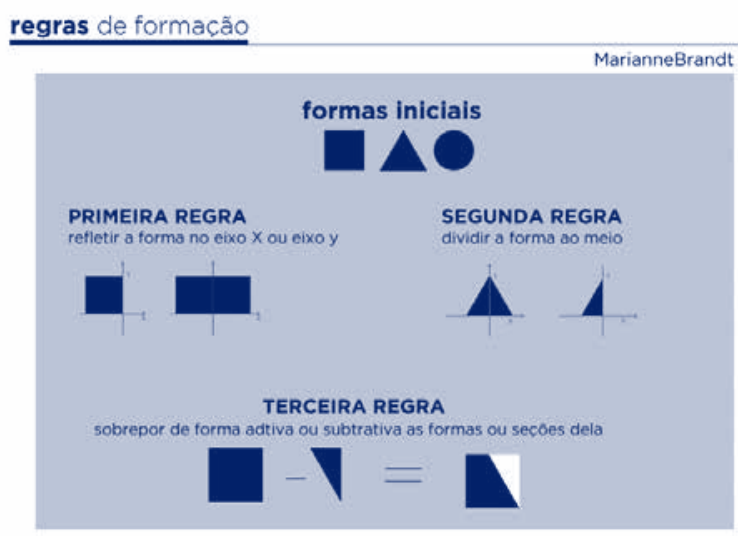

Figure 1.l: Regras identificadas nas obras de Marianne Brandt análiseformal

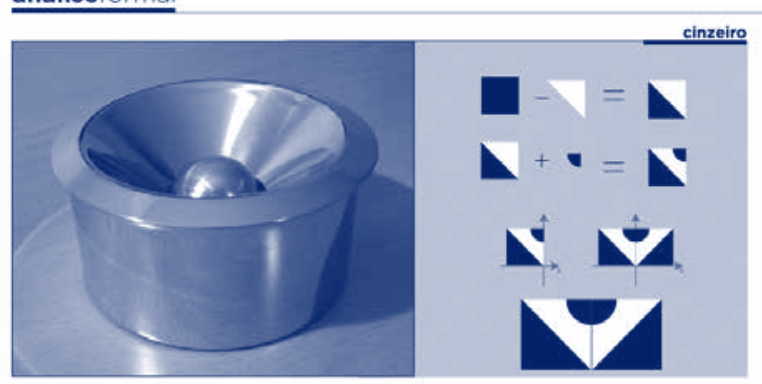

Figural.2: Análise formal da obra Cinzeiro feito por Marianne Brandt, 1926. 
escolha do material e as possibilidades que ele oferece (no caso, o aço tubular). É comum em sua obra uma noçâo de continuidade da estrutura, propiciada pelas curvas das "linhas" nas "quinas" dos seus projetos, como a Cadeira Cesca (1928), que também servem de apoio para os "retângulos" e para o próprio objeto em relação ao chão (Figura 2.2).

\section{Resultados}

Após a realização dos processos de análise descritos, concluiu-se que, mesmo que os pressupostos da gramática da forma não estivessem inteiramente teorizados à época, pode-se atestar a influência de um vocabulário de formas e regras de aplicaçáo deste no processo de concepçáo de projeto desses artistas específicos da Bauhaus.

Por meio da identificação analítica de possíveis regras utilizadas pelos designers escolhidos, foi possível a síntese de novos mobiliários e também de um experimento estético. As gramáticas formais identificadas serviram como referência a fim de manter uma unidade que garantisse uma estética semelhante a dos mobiliários analisados previamente. Entretanto, no desenvolvimento do experimento estético, a coerência formal não foi um objetivo, mas sim atestar o papel do designer como manipulador da gramática da forma na concepção de um projeto.

A partir da regras de formação identificadas nas obras de Marianne Brandt e da aplicação de regras gerais de composição, foi possível projetar uma luminária, a qual possui a mesma lingua-

\section{$\underline{\text { regras de formaçán }}$}

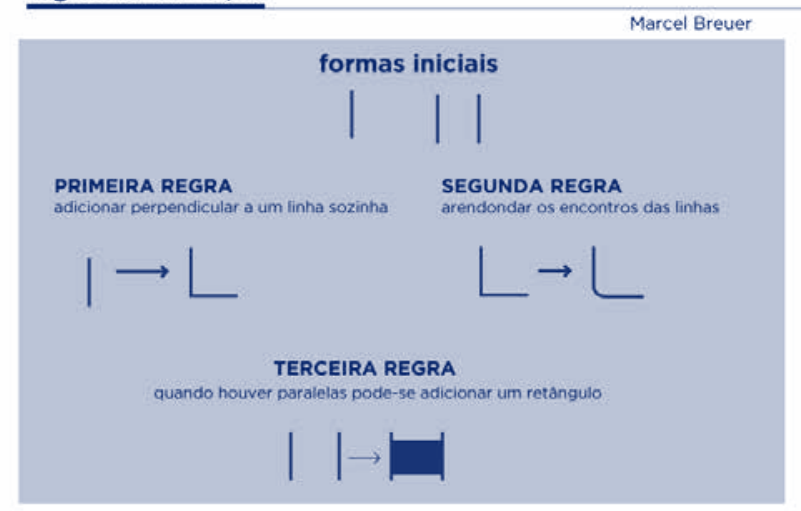

Figura 2.l: Regras identificadas nas obras de Marcel Breuer.

análiseformal

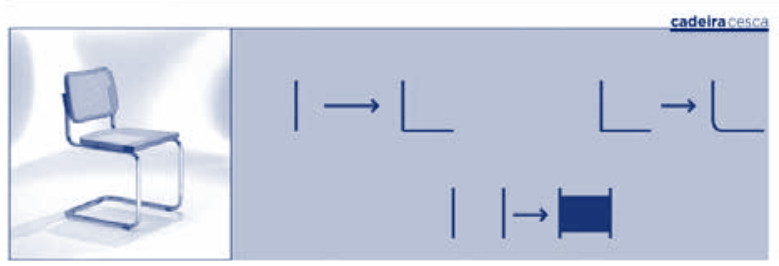

Figure 2.2: Análise da obra Cadeira Cesca desenvolvida por Marcel Breuer,1928. gem formal dos outros produtos da artista, provando o potencial generativo das gramáticas formais. Após a concepção, o objeto foi modelado em 3D no programa Rhinoceros e renderizado no programa KeyShot (Figura 3).

A partir da gramática identificada na obra de Marcel Breuer, foi estabelecido um diálogo entre essas regras e uma experimentaçáo formal com algoritmos paramétricos a fim de desenvolver um resultado primordialmente estético. Estabeleceu-se um módulo inicial (quatro linhas para formar um quadrado e este sendo preenchido) para começar a experimentaçáo formal em ambiente Grasshopper. Utilizaram-se as regras identificadas para criação do módulo inicial, utilizando linhas e retângulos. Entretanto, optou-se por quebrar a noção de continuidade, fazendo com que as linhas estruturais saíssem de um "núcleo". Em seguida, foram aplicadas regras de composição como multiplicação, reflexão e rotação do módulo, obtendo resultados com força estética, semelhante a uma criatura aquática. Devido à semelhança formal a uma criatura do filo dos Cnidários, foi dada a obra do nome de Cnidaria. Ela se apresenta como um sistema autopoiético, que pode se auto-gerir e se autorregular, podendo assumir uma variadade de composiçóes devido a seu caráter paramétrico (Figura 4).

Com base no processo descrito anteriormente, apropriou-se da Biomimética como técnica de processo criativo, estabelecendo alguns parâmetros formais para a geração de variadas composiçóes estéticas. A Biomimética é uma área que estuda a natureza e seus princípios e padróes em busca de soluçóes, reproduzindo-os na prática projetual. Segundo Forcellini (2002), há pesquisas que indicam que a criatividade para encontrar soluçóes de projeto de produtos nasce, com frequência, na analogia direta com a natureza.

O estudo atesta ainda a importância da influência do Designer no processo de concepção do seu projeto. A utilização da gramática da forma não se configura apenas como uma mera aplicaçáo de regras, como é mostrado no experimento estético Cnidaria. O designer entra como peça-chave, com sua subjetividade e seu repertório, escolhendo o vocabulário formal que melhor lhe convém, as regras que pretende aplicar, definindo a forma inicial e decidindo até onde quer chegar. Por mais que esse processo possa parecer genérico, por ser realizado com o auxílio de regras e um vocabulário pré-definido, trará sempre a necessidade de regência por parte do desenvolvedor.

\section{Conclusão}

Após a realização de análises teóricas e práticas sobre a gramática da forma, tanto a abordagem analítica como a generativa, e sua relaçáo com o projeto em design, pode-se atestar sua importância como ferramenta projetual. Por meio de um estudo mais específico sobre a produção artística de Marianne Brandt e Marcel Breuer, é possível identificar um vocabulário e uma unidade formal, provando que, mesmo não estando teorizada à época, a gramática da forma é uma ferramenta intuitiva e pode suprir as demandas de um projeto, sejam elas de caráter funcional ou estético. Entretanto, não se deve pensar nela como sendo uma mera aplicação mecânica de um vocabulário de formas e regras, pois o repertório, os conceitos, a ideias, em resumo, a subjetividade do projetista influenciam fortemente em cada etapa do processo de aplicaçáo dessa ferramenta. 


\section{luminária projetada}

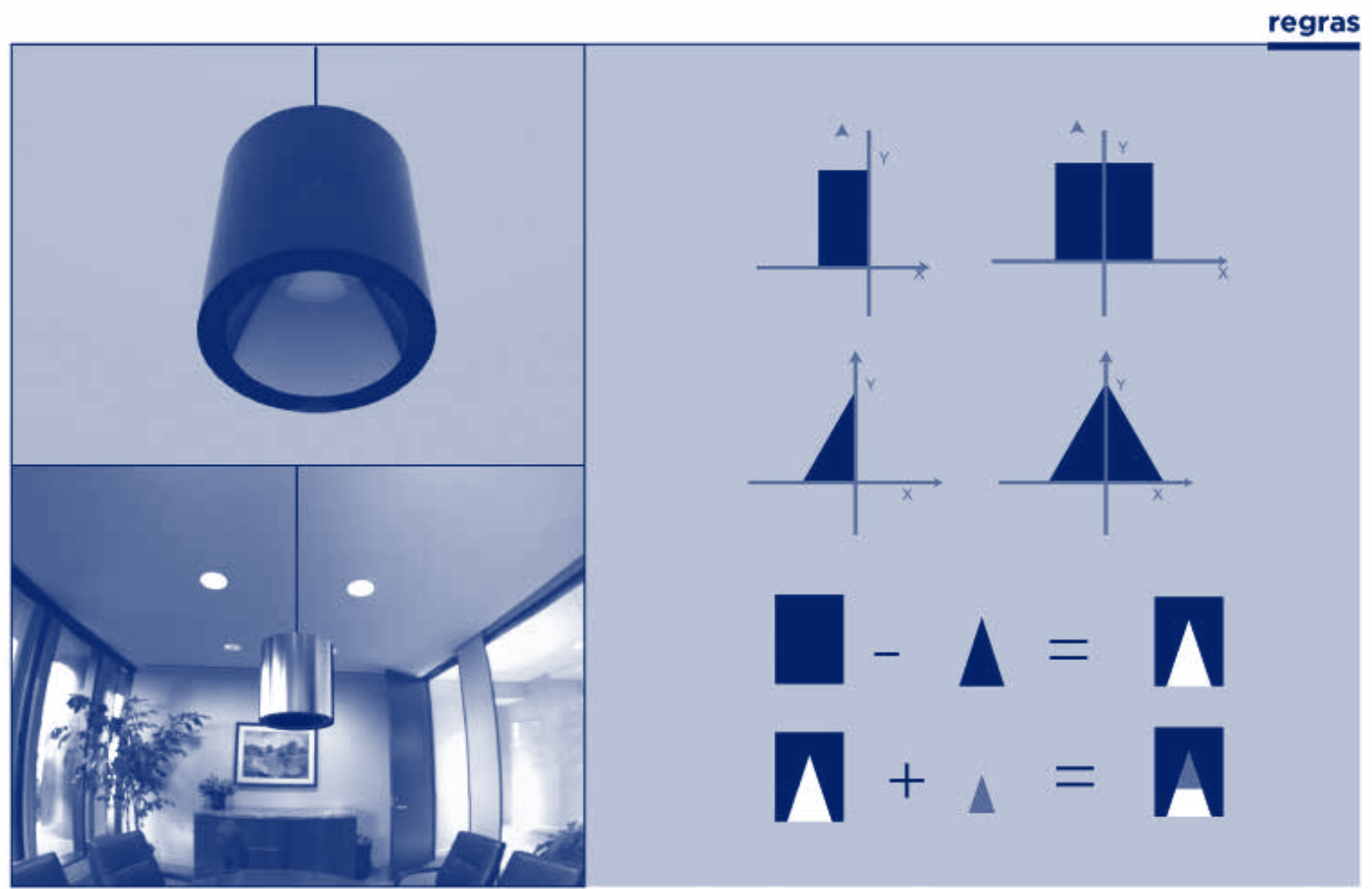

Figure 3: Á esquerda, renders da luminária projetada. À direita, regras de formaçâo utilizadas no processo de concepção do produto.

\section{experimentação estética}

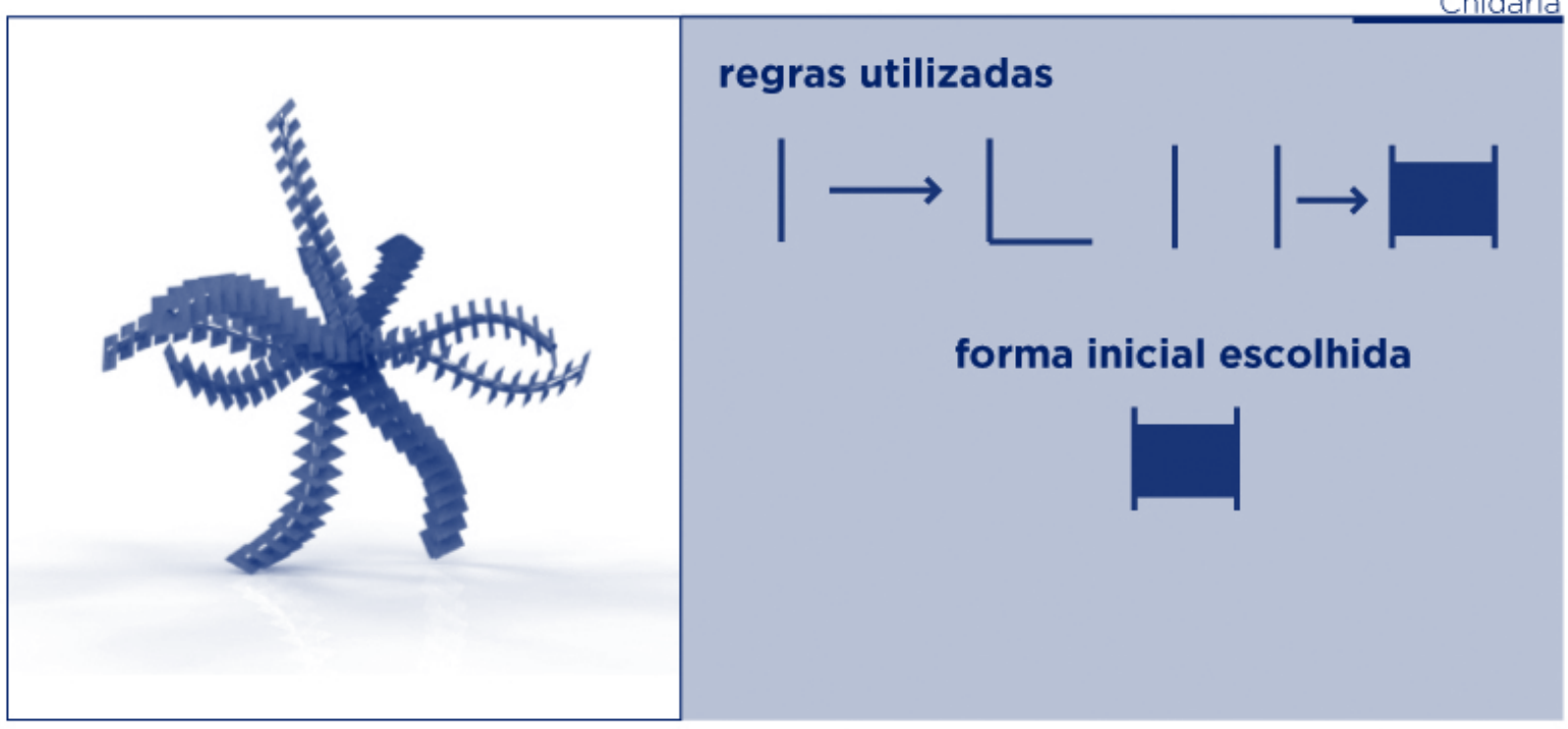

Figure 4: Regras e render da experimentaçâo estética Cnidaria inspirada na gramática formal identificada nas obras de Marcel Breuer. 


\section{Referência}

CELANI, G.; CYPRIANO D.; GODOY G.; VAZ C.E.: 2006, A gramática da forma como metodologia de análise e síntese em arquitetura, Conexão (Caxias do Sul), v. 5.

BONSIEPE, Gui. As sete colunas do Design. In Do Material ao Digital, 1997.

MITCHELL, William J. A Lógica na Arquitetura. Campinas: Editora Unicamp, 2008.

VASCONCELLOS, Maria José Esteves de. Pensamento sistêmico: o novo paradigma da ciência. Sáo Paulo: Papirus, 2005.

LUPTON, E.; ABBOT MILLER, J. ABC da Bauhaus: a Bauhaus e a teoria do design. Sáo Paulo: Cosac Naify, 2008.

KNIGHT, Terry.Transformation in Design: A Formal Approach to Stylistic Change and Innovation in the Visual Arts. Cambridge: Cambridge University Press, 2004.

WOODBURRY, Robert. Elements of parametric design. New York: Routledge, 2010.

MATURANA, H.R. \& VARELA, F.J - A Árvore do Conhecimento: as bases

biológicas da compreensão humana. Tradução; Humberto Mariotti e Lia Diskin. São

Paulo, Pala Athenas, 2001;

http://www.geocities.com/pluriversu/autopoies.html. Acesso em 04 de março de 2014.

http://graphics.sabanciuniv.edu/cs450-projects/t_blockweb/project\%20report.pdf. Acesso em 04 de março de 2014.

http://interface-design.co.uk/blog/the-bauhaus-in-design/. Acesso em 04 de março de 2014.

http://www.westwing.com.br/magazin/historias/mies-van-der-rohe/. Acesso em 04 de março de 2014.

http://stuff.mit.edu/afs/athena/course/4/4.561/old/week7-grammarfinal-pdf-public/team_Mies_final.pdf. Acesso em 04 de março de 2014.

http://www.mackenzie.br/dhtm/seer/index.php/cpgau/article/ viewFile/Alves.2012.1/64. Acesso em 04 de março de 2014. www.patrikschumacher.com/Texts/Parametricism and the Autopoiesis of Architecture.html. Acesso em 04 de março de 2014 STINY, G.; GIPS, J. Shape Grammars and the Generative Specification of

Painting and Sculpture, in C V Freiman (ed) Proceedings of IFIP Congress 71

(Amsterdam: North-Holland) 1460- 1465. Republished in O R Petrocelli (ed),

The Best Computer Papers of 1971 (Philadelphia: Auerbach) pp125-13, 1971.

STINY, G. Two exercises in formal composition. Environment and Planning B,

v. 3, p. 187-210, 1976.

STINY, G. Kindergarten grammars: designing with Froebel's building gifts.

Environment and Planning B, v. 7, p. 409-462, 1980.

http://www.mit.edu/\%7Etknight/IJDC/frameset_abstract.htm. Acesso em 30 de agosto 2014

http://www.shapegrammar.org. Acesso em 30 de agosto 2014. 